\title{
Improved Control of DFIG during Grid Voltage Distortion for Reduction of Current Harmonic Using PI-Fuzzy
}

\author{
Hai Nguyen Thanh ${ }^{1,2 *}$ \\ ${ }^{1}$ HCMC University of Technical and Education, Ho Chi Minh City, Vietnam. \\ ${ }^{2}$ Le Hong Phong High School for the Gifted, Ho Chi Minh City, Vietnam. \\ * Corresponding author. Tel. +84903699664; email: hai_nguyenthanh2012@yahoo.com.vn \\ Manuscript submitted December 1, 2014; accepted August 31, 2015. \\ doi: 10.17706/ijcee.2015.7.5.335-349
}

\begin{abstract}
This paper presents a new vector Hysteresis Current Control (HCC), which is applied on a three-phase three-level Voltage Source Inverter (VSI) and eliminate rotor currents harmonics using PI-Fuzzy controller (PI-F). The proposed control technique is used to control the active and reactive power of wind turbines by means of controlling the rotor currents of the Doubly Fed Induction Generator (DFIG) during grid voltage distortion for reduction of current harmonic using PI-F. These control techniques use single or multiple applications of hybrid PI-F with anti-windup and Notch filter to eliminate the second-order harmonic components and negative sequence components. In the newly proposed SFOC-based scheme, PI controllers with Fuzzy, Notch filters and the Sequence Component Controller (SCC) are utilized. The designed system consists of an induction generator with slip ring and power-electronics converters at both rotor and grid sides. The modifications are applied to the Rotor Side Converter (RSC). Simulations in Matlab/Simulink illustrate the enhanced stability of torque, active and reactive powers delivered by DFIG in both the PWM controller (PWM) and HCC schemes. Moreover, comparisons in simulation results, obtained separately from all the presented control structures, are provided to evaluate the effectiveness of the newly proposed scheme.
\end{abstract}

Key words: DFIG, fuzzy logic control, PWM current controller, hysteresis current controller, SFOC.

\section{Introduction}

DFIG has been commonly used in wind power generation due to the advantage of low rating of power-electronics circuits needed to independently control of active and reactive powers delivered to the grid [1]. However, it happens very often that the grids experience the problems of voltage unbalance, which raise the winding temperature and cause pulsations of torque and power, oscillations of stator/rotor currents, the electrical stress on the RSC and the mechanical stress on the gear box [2], [3].

In fact, there have been several modifications proposed to ameliorate the performances of the DFIG based wind turbines during grid voltage distortion. Current controllers are designed to control positive and negative sequences of the rotor current on the basic of machine models in positive and negative d-q reference frames in order to achieve four targets such as: the balance of stator current, constant output active power, invariant electromagnetic torque for reducing the mechanical stress, and oscillation of the rotor current [4]. In detail, both positive and negative sequence components are used in this scheme. Referring in [5], [6], dynamic programming power control plus which applies the Bellman theory for optimal control of discrete time systems is suggested to obtain correctly the converter switching sequence 
for controlling the decoupled active and reactive powers under the network unbalance condition. The optimum policy is determined from the pre-defined quadratic time-domain performance criterion and cost function for any operating point [7].

The stator voltage's magnitude is determined by the exchange of reactive power between generator and the grid while the phase difference is controlled by active power [4]. Therefore, power balance must be maintained on the grid. A voltage drop proportional to current and radial distance to the substations happens when a fault occurs. Due to the remote location of wind farms, the voltage difference may be well out of the limits and this could result in multiple disconnections on the wind farms [4].

The active power delivered to the grid by generator depends on the input mechanical power provided by the wind turbine. Therefore, a mismatch in power supply and demand on the distribution network could lead to a change in rotational energy stored in the generator. This will cause a decrease in frequency if the power supply is insufficient and an increase in frequency if the power supply is excessive [4].

A modified control scheme to reduce the over current and over DC link voltage of the converters during grid voltage disturbance has been proposed for Stator Flux Oriented Control (SFOC) by considering the dynamic response of magnetizing current [8]. The effect of the core saturation on the performance of DFIG during voltage unbalance is also investigated [9]. A new model of DFIG whose magnetizing inductance is a function of magnetizing current is developed to propose a new control scheme, considering the dynamic response of magnetizing current to compensate the effect of core saturation [9]. However, the complexity of this control system will increase with the inclusion of magnetizing current's dynamic control

\section{Doubly Fed Induction Generator Modeling}

This section discusses the control structure for vector control of grid connected doubly fed induction generator. The control methods in [6], [8], [9] are based on SFOC, while the methods in [7] and this paper are on SFOC with SCC and PWM/HCC using PI-F.

Dynamic model of DFIG with balanced grid voltage in a generally rotating reference frame dq [2] are considered in this paper. Furthermore, positively and negatively rotating reference frames, which are denoted as $d q+$ and $d q$ - respectively, are also used to develop control model for DFIG during unbalanced voltage dip. These reference frames are presented in the Fig. 1.

In SFOC reference frame, where the $d$ axis is attached the stator flux space vector, the following characteristics are obtained:

$$
\psi_{d s}=\left|\psi_{s}\right|=L_{m} i_{m s}, \psi_{q s}=0
$$

The stator voltage equations and stator current of DFIG in a generally rotating reference frame $d q$ as shown in equations (2.1), (2.2)

$$
\begin{gathered}
v_{d s}=R_{s} i_{d s}-\omega_{s} \psi_{q s}+\frac{d \psi_{d s}}{d t} \\
v_{q s}=R_{s} i_{q s}+\omega_{s} \psi_{d s}+\frac{d \psi_{q s}}{d t} \\
I_{s}=\frac{\left(\psi_{s}-L_{m} I_{r}\right)}{L_{s}}
\end{gathered}
$$




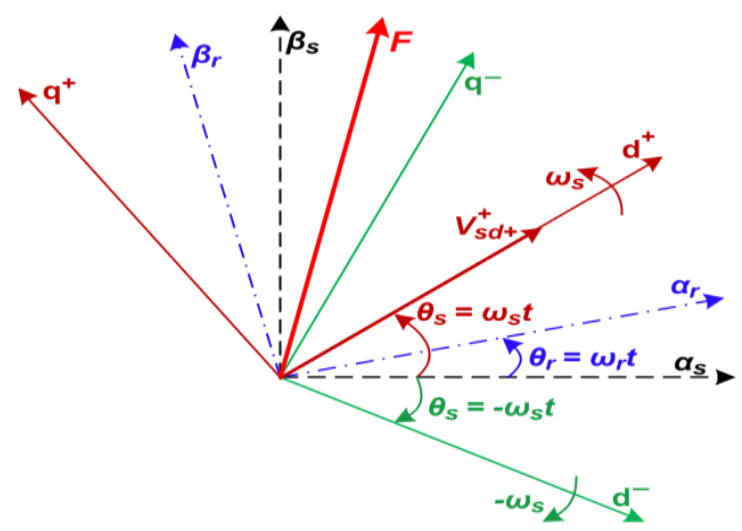

Fig. 1. Relationships between $(\alpha, \beta) s,(\alpha, \beta) r, d q+$ and $d q-$ reference frames [10].

\subsection{Balanced Network Voltage}

If the $d$-axis of the reference frame is fixed to the stator flux rotating at the synchronous speed of equations in the new reference frame can be derived by simply replacing with in (1), (2.1), (2.2), (2.3), and Fig. 1. The equations for active and reactive powers in the stator flux reference frame are shown in equation (3.1) and (3.2)

$$
\begin{aligned}
& P_{s}=\frac{3}{2}\left(v_{d s} i_{d s}+v_{q s} i_{q s}\right)=\frac{3}{2} v_{q s} i_{q s}=-\frac{3}{2}\left|V_{s}\right| \frac{L_{m}}{L_{s}} i_{q r} \\
& Q_{s}=\frac{3}{2}\left(v_{q s} i_{d s}-v_{d s} i_{q s}\right)=\frac{3}{2} v_{q s} i_{d s}=\frac{3}{2}\left|V_{s}\right| \frac{L_{m}}{L_{s}}\left(\frac{\left|V_{s}\right|}{\omega_{s} L_{m}}-i_{d r}\right)
\end{aligned}
$$

The equations above have shown that independent control of $P$ and $Q$ can be by controlling $i_{d r}$ and $i_{q r}$ in SFOC.

\subsection{Unbalanced Network Voltage}

Assuming no zero sequence components, the three phase quantities such as voltage, current, and flux may be decomposed into positive and negative sequence components when the network is unbalanced. In the stationary reference frame, the voltage, current, and flux can be decomposed into positive and negative sequence components as [6]

$$
I_{\alpha \beta}(t)=I_{\alpha \beta+}(t)+I_{\alpha \beta-}(t)
$$

According to Fig. 1 , the transformation between $(\alpha, \beta),(d q)^{+}$and $(d q)^{-}$reference frames are given by

$$
\begin{gathered}
I_{d q}^{+}=I_{(\alpha \beta) s} e^{-j \varpi_{s} t}, I_{d q}^{-}=I_{(\alpha \beta) s} e^{j \varpi_{s} t} \\
I_{d q}^{+}=I_{(\alpha \beta) s} e^{-j 2 \omega_{s} t}, I_{d q}^{-}=I_{(\alpha \beta) s} e^{j 2 \varpi_{s} t}
\end{gathered}
$$

According to (4), (5.1), (5.2) and Fig. 1 the rotor current are give by

$$
I_{d q r}^{+}=I_{d q r+}^{+}+I_{d q r-}^{+}=I_{d q r+}^{+}+I_{d q r-}^{-} e^{-j 2 \omega_{s} . t}
$$


When unbalanced voltage, the equations for active and reactive powers in the stator [6]; [7].

$$
\begin{aligned}
& P_{s}=P_{s 0}+P_{s_{-} \sin 2} \sin \left(2 \varpi_{s} t\right)+P_{s_{-} \cos 2} \cos \left(2 \varpi_{s} t\right) \\
& Q_{s}=Q_{s 0}+Q_{s_{-} \sin 2} \sin \left(2 \varpi_{s} t\right)+Q_{s_{-} \cos 2} \cos \left(2 \varpi_{s} t\right)
\end{aligned}
$$

With

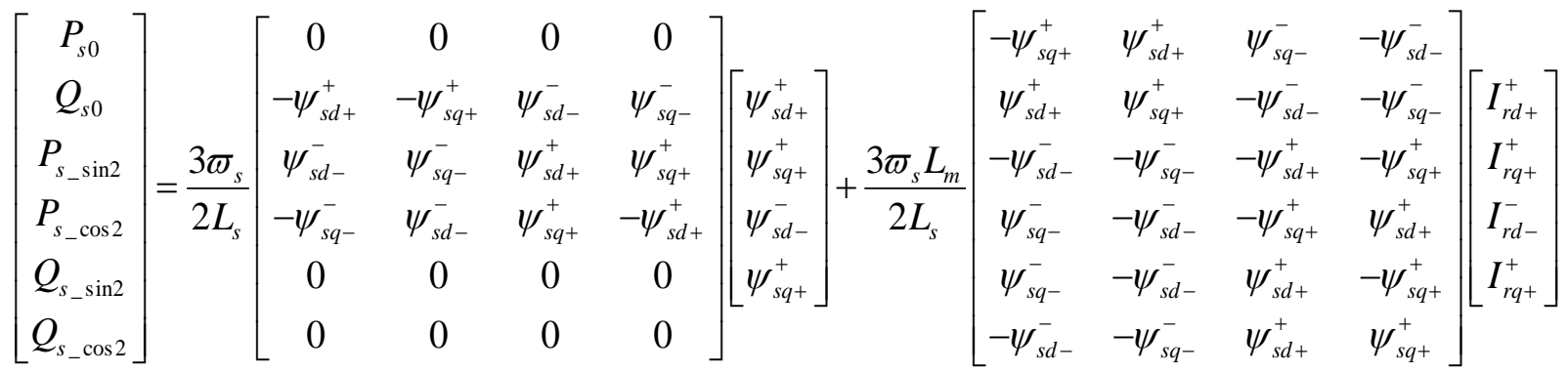

The total power imported from the rotor shaft equals to the sum of the power outputs from the equivalent voltage source $j \omega_{S} \psi_{s}$ and $j\left(\omega_{S}-\omega_{R}\right) \psi_{r}$.

$$
P_{e}=-\frac{3}{2} \operatorname{Re}\left[j \omega_{s} \cdot \psi_{s}^{+} \cdot \hat{I}_{s}^{+}+j\left(\omega_{s}-\omega_{r}\right) \cdot \psi_{r}^{+} \cdot \hat{I}_{r}^{+}=\frac{3}{2} \omega_{r} \operatorname{Re}\left[j \psi_{s}^{+} \hat{I}_{r}^{+}\right]=P_{e 0}+P_{e_{-} \sin 2}+P_{e_{-} \cos 2}\right.
$$

where

$$
\left[\begin{array}{c}
P_{e 0} \\
P_{e_{-} \sin 2} \\
P_{e_{-} \cos 2}
\end{array}\right]=\frac{3 L_{m} \varpi_{r}}{2 L_{s}} \cdot\left[\begin{array}{cccc}
-\psi^{+}{ }_{s q+} & \psi^{+}{ }_{s d+} & -\psi^{-}{ }_{s q-} & \psi^{-}{ }_{s d-} \\
\psi^{-}{ }_{s d-} & \psi^{-}{ }_{s q-} & -\psi^{+}{ }_{s d+} & -\psi^{+}{ }_{s q+} \\
-\psi^{-}{ }_{s q-} & \psi^{-}{ }_{s d-} & -\psi^{+}{ }_{s q+} & \psi^{+}{ }_{s d+}
\end{array}\right] \cdot\left[\begin{array}{l}
I_{r d+}^{+} \\
I_{r q+}^{+} \\
I_{r d-}^{-} \\
I_{r d-}^{-}
\end{array}\right]
$$

The electromagnetic torque of the DFIG is calculated as

$$
T_{e}=\frac{P_{e}}{\omega_{r}}=\frac{\left(P_{e 0}+P_{e_{-} \sin 2}+P_{e_{-} \cos 2}\right)}{\omega_{r}}
$$

\section{The Proposed Control Methods}

\subsection{Previously and Newly Proposed Control Schemes}

The structure of our formerly modified control method with SFOC for DFIG is represented [11]. The modified control scheme previously and newly proposed one with SFOC are illustrated by Fig. 2 and Fig. 3, respectively. Converters on the rotor side of DFIG are controlled to achieve the independent control of active and reactive powers.

According to [11], the control system, using hybrid PI-Fuzzy controller, has provided better performances 
of the generated powers. However, this is only verified with the balanced grid voltage. To enhance the stability of the powers during voltage unbalance situation, the inclusion of Notch filter has been suggested by [12] and shown in Fig. 2 and Fig. 3. Notch filters are used to eliminate second-order harmonic components in positive and negative sequences of the stator voltage. For the scheme in Fig. 2 and Fig. 3, Notch filters are used with the positive sequence of stator voltage and the negative sequence of the rotor current [12].

In Fig. 2 and Fig. 3, the control scheme proposed in this study, applies SCC to eliminate the negative sequences of the stator voltage which cause distortions in power responses. Additionally, Notch filter is also used to eliminate the second-order harmonic component in the stator voltage. This suggested control scheme reduces the number of current sensors and Notch filter. The decreased amount of computational tasks is achieved with PI controllers with Fuzzy.

\subsection{PI-F for the Scheme in Fig. 2 and Fig. 3}

PI-F as shown in Fig. 4 are used to control the errors between the required and actual values of both the active power and reactive power delivered to the grid by the generator. The parameters of the PI-F are adjusted by the fuzzy rules to obtain the best output to drive the errors to zero. The output of these controllers are commanded values of $\mathrm{d}$-q components of rotor current in the stator flux oriented reference frame. These commanded values of currents are used to regulate the RSC for provision of the rotor phase voltage to DFIG [11].

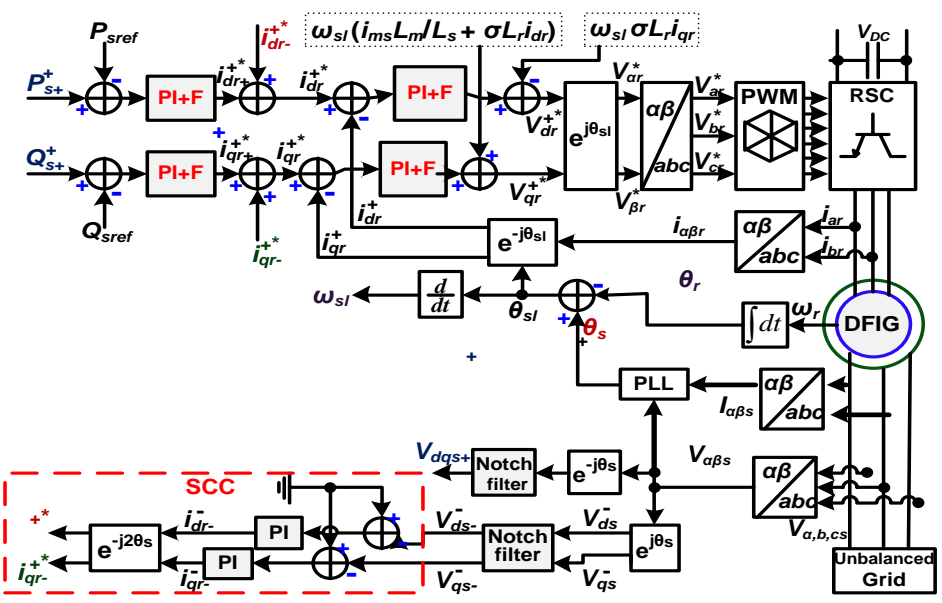

Fig. 2. Proposed control structure with PWM, SCC and PI-F.

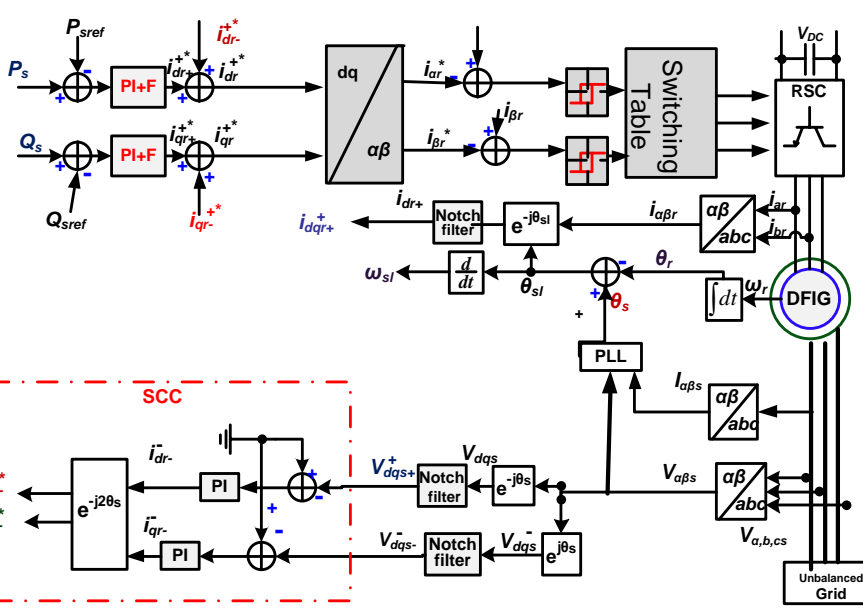

Fig. 3. Proposed control structure with HCC, SCC and PI-F. 


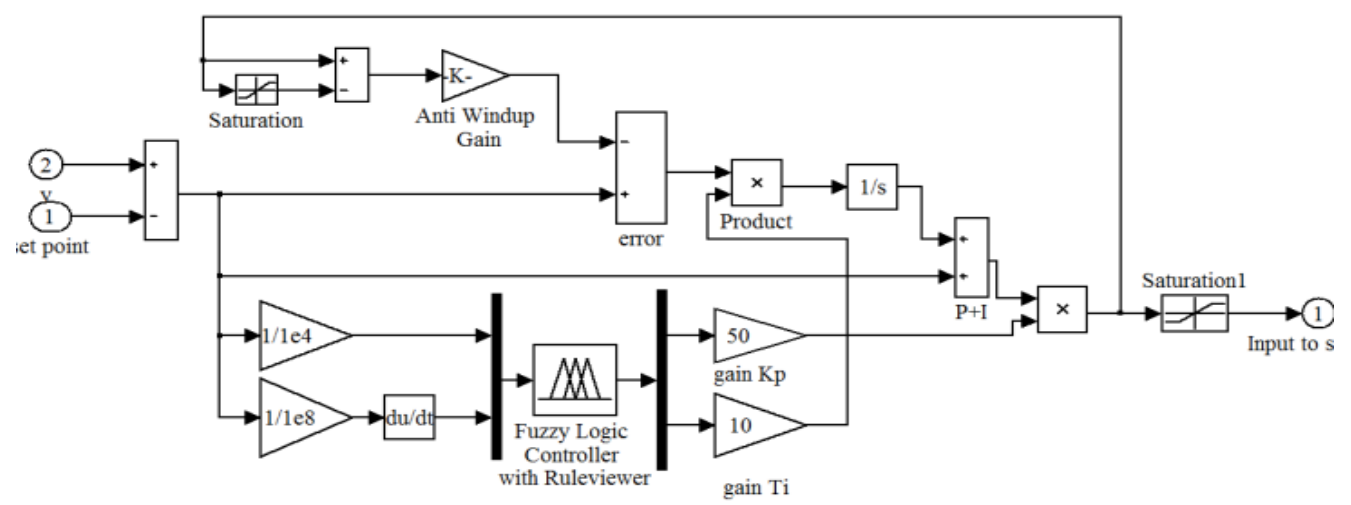

Fig. 4. PI-fuzzy controller [12].

\subsection{Hysteresis Current Control for the Scheme in Fig. 3}

The block diagram of the rotor side converter control is shown in Fig. 3. The active and reactive powers are compared to their references, and then two PI controllers are used. The outputs of the two PI-F represent the direct and quadrature components of the current references. The rotor currents of the DFIG are compared to their references after being sensed and transformed to dq reference frame. The two DC capacitors, which supply the three-level VSI, are assumed with great value in order to neglect the DC capacitor unbalance [13], [14]. The three phase three-level VSI has three switching commutation cells; each one contains four IGBT and two neutral clamping diodes (Fig. 5).

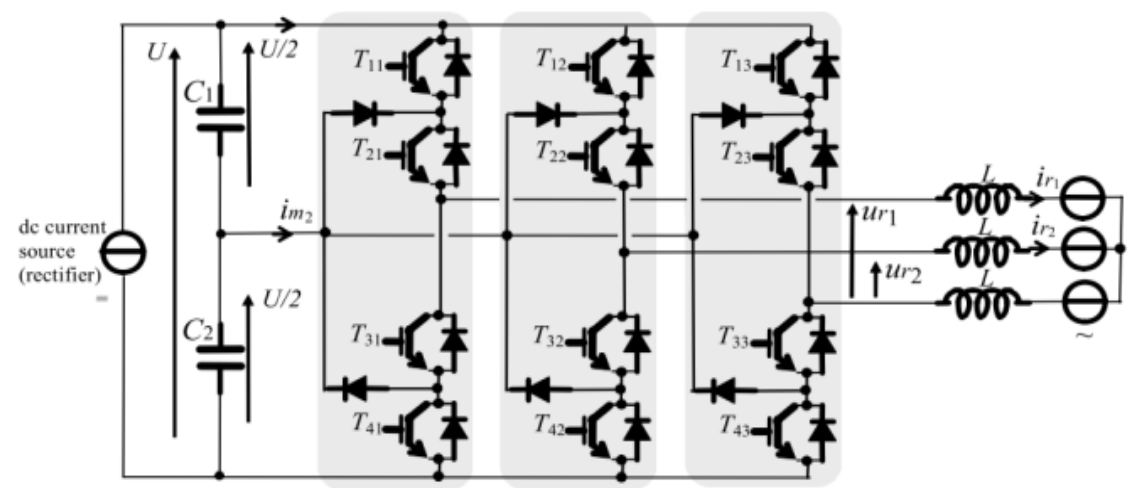

Fig. 5. Three-phase three-level VSI [13].

\subsection{Modifications in the Newly Proposed Scheme}

The newly proposed scheme also include a SCC which help to eliminate the negative sequence components of the fundamental frequency and all the harmonics components of stator voltage. The Notch filters are assigned to remove the negative sequence components which cause oscillation in active power, reactive power, and electromagnetic torque according to equations (8) and (9) [4].

The newly proposed scheme is different to the methods in [6] and [7]. However, reference values of $I_{d q r+}^{+}$ are the output of two PI controllers with fuzzy, as shown in Fig. 3, instead of being calculated from equation (6) as in [12]. The PI-F will provide the independence with parameter variations for the commanded values of $I_{d q r+}^{+}$. Robust responses of $I_{d q r+}^{+}{ }^{*}$ the variation of $P^{*}, Q^{*}$ can also be obtained with PI controllers with fuzzy. Eliminate Harmonic Negative Sequence Components of Rotor Currents $\left(I_{d q r-}^{-}=0\right)$ in SCC and with 
SFOC $\psi_{q r}^{+}=0$. The oscillation in these equations happens at twice the frequency of the positive sequence component. However, the performance of digitally designed Notch filters is not perfect. Therefore, the inclusion of SCC helps to clear all the negative sequence components. With $I_{d q r-}^{-}=0, \psi_{q r}^{+}=0$ and (6), rotor current given by

$$
I_{d q r}^{+} \approx I_{d q r+}^{+}
$$

Substituting (1), (7) and (12) the equations for active and reactive powers in the stator

$$
\begin{gathered}
P_{s+}^{+}=1.5\left(V_{d s+}^{+} I_{d s+}^{+}+V_{q s+}^{+} I_{q s+}^{+}\right) \\
Q_{s+}^{+}=1.5\left(V_{d s+}^{+} I_{q s+}^{+}-V_{q s+}^{+} I_{d s+}^{+}\right)
\end{gathered}
$$

SCC also functions as a current controller using PI-F to regulate the positive sequence components of rotor current. Negative sequence components of rotor current will increase the power rating of RSC if being used to control generator's active and reactive power [4].

A totally different current control method, which is hysteresis control, is also presented in this paper as shown in Fig. 4.

The application of Notch filters for removing the $2^{\text {nd }}$ harmonic order is the similarity between the proposed ones and schemes in [6], [7].

The values of $i_{d r-}^{+*}, i_{q r-}^{+*}$ and then $i_{d r}^{+*}, i_{q r}^{+*}$ as in Fig. 3 and Fig. 4 can be done by using (14.1) and (14.2).

$$
\begin{aligned}
& i_{d r}^{+^{*}}=i_{d r+}^{+^{*}}+i_{d r-}^{+^{*}}=i_{d r+}^{+^{*}}+i_{d r-}^{-^{*}} e^{-j 2 \theta_{s}} \\
& i_{q r}^{+^{*}}=i_{q r+}^{+^{*}}+i_{q r-}^{+^{*}}=i_{q r+}^{+^{*}}+i_{q r-}^{-^{*}} e^{-j 2 \theta_{s}}
\end{aligned}
$$

The next session will verify the performance of the proposed methods.

\section{Simulation Results}

Simulations of the proposed control methods for the 2.3MW grid-connected DFIG are carried out with the generator's parameters as given by Table 1. The commanded values of $P$ and $Q$ are changed after 50s, reference value of $P$ is changed from 1.5 MW to $2.0 \mathrm{MW}$ while the reference value of $Q$ is changed from 1.2 MVAR to 800 KVAR. The grid voltages are balanced until the 60th second (Fig. 6), one of the phase voltages is reduced by $10 \%$, and then they are balanced again from the 80 th second. The proposed control methods are for variable speed and constant frequency of DFIG, without loss of generality, the rotor speed in the simulation is super-synchronous and at a particular value of $1400 \mathrm{rpm}$. The wind speed's variation is shown in Fig. 7.

The mean, maximum, and minimum values of the active power, reactive power and machine's torque during the unbalanced voltage from the $65^{\text {th }}$ second to the $75^{\text {th }}$ second are represented in Tables 2 and 3 . In detail, the statistics of operations at the sub-synchronous speed $n_{r}=1400 \mathrm{rpm}$ are also illustrated by these tables. 
Table 1. Parameters of the 2.3mw DFIG

\begin{tabular}{|l|l|l|}
\hline Parameter & Symbol & Value \\
\hline Stator inductance & $L_{S}$ & $159.2(\mu \mathrm{H})$ \\
\hline Rotor inductance & $L_{r}$ & $159.2(\mu \mathrm{H})$ \\
\hline Magnetic inductance & $L_{m}$ & $5.096(\mathrm{mH})$ \\
\hline Stator resistance & $R_{S}$ & $4(\mathrm{~m} \Omega)$ \\
\hline Rotor resistance & $R_{r}$ & $4(\mathrm{~m} \Omega)$ \\
\hline Number of pole pairs & $P$ & 2 \\
\hline Frequency (angular) & $\omega_{S}$ & $100 \pi(\mathrm{rad} / \mathrm{s})$ \\
\hline Inertia & $J$ & $93.22\left(\mathrm{~kg} . \mathrm{m}^{2}\right)$ \\
\hline Inertia of Rotor & $J_{\text {rot }}$ & $4.17 .10^{6}\left(\mathrm{kgm}^{2}\right)$ \\
\hline
\end{tabular}
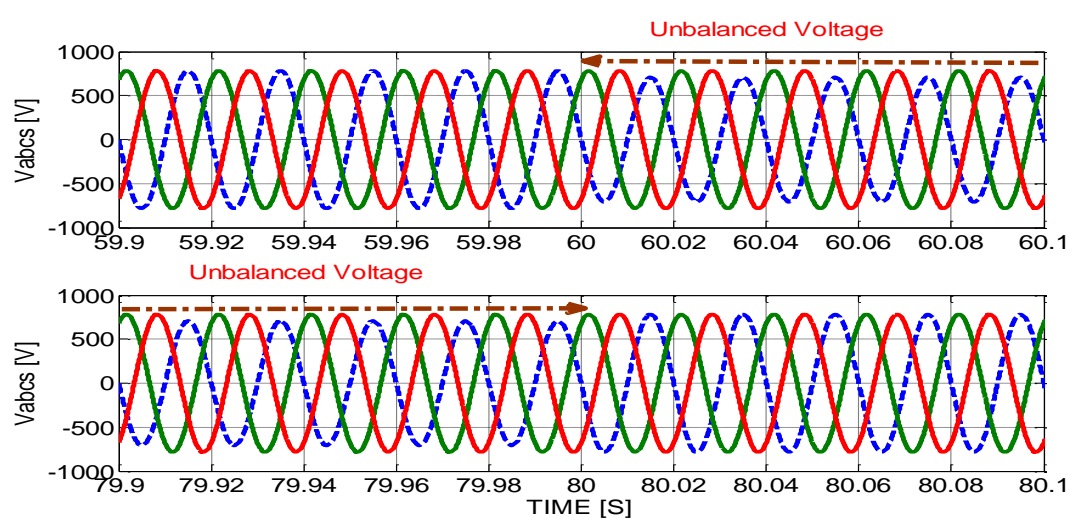

Fig. 6. The grid voltages are balanced until the 60th second.

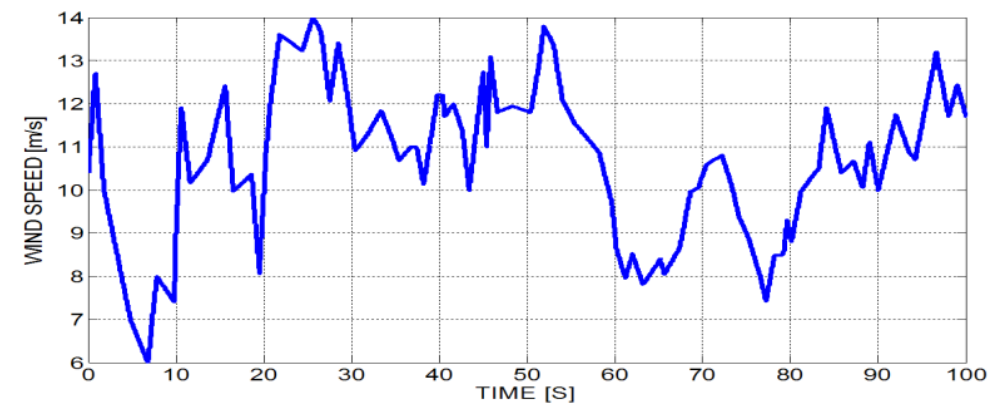

Fig. 7. Random variation of the wind speed.

Table 2. Average Values of Active Power $(P S)$ in the Steady State for Five Controllers

\begin{tabular}{|c|c|c|c|c|c|c|}
\hline \multirow{2}{*}{$\begin{array}{c}\text { Active Power } \\
\left(\mathbf{P}_{\text {sref }}=2 \mathrm{MW}\right)\end{array}$} & \multicolumn{3}{|c|}{ With SCC\&PI-F (PWM) } & \multicolumn{3}{c|}{ With SCC\&PI-F (HCC) } \\
\cline { 2 - 7 } & Min & Mean & Max & Min & Mean & Max \\
\hline Unbalanced & $-\mathbf{2 . 0 6}$ & -2 & -1.95 & -2.01 & -2 & -1.99 \\
\cline { 2 - 7 }$\left(\mathbf{6 5}^{\text {th }}-\mathbf{- 7 5}^{\text {th }}\right) \mathrm{s}$ & $\mathbf{3 \%}$ & $\mathbf{0 \%}$ & $\mathbf{- 3 \%}$ & $0 \%$ & $\mathbf{0 \%}$ & $-1 \%$ \\
\hline & Deviation $=\frac{P_{S}-P_{\text {Sref }}}{P_{\text {Sref }}}(\%)$
\end{tabular}

Table 3. Average Values of Reactive Power $(Q s)$ in the Steady State for There Controllers

\begin{tabular}{|c|c|c|c|c|c|c|}
\hline \multirow{2}{*}{$\begin{array}{c}\text { Reactive Power } \\
\left(Q_{\text {sref }}=-0.8 \text { MVAR }\right)\end{array}$} & \multicolumn{3}{|c|}{ With SCC\&PI-F (PWM) } & \multicolumn{3}{|c|}{ With SCC\&PI-F (HCC) } \\
\hline & Min & Mean & Max & Min & Mean & Max \\
\hline Unbalanced & -0.84 & -0.79 & -0.77 & -0.82 & -0.8 & -0.79 \\
\hline$\left(65^{\text {th }}-75^{\text {th }}\right) \mathrm{s}$ & $5 \%$ & $-1 \%$ & $-4 \%$ & $2 \%$ & $0 \%$ & $-1 \%$ \\
\hline
\end{tabular}




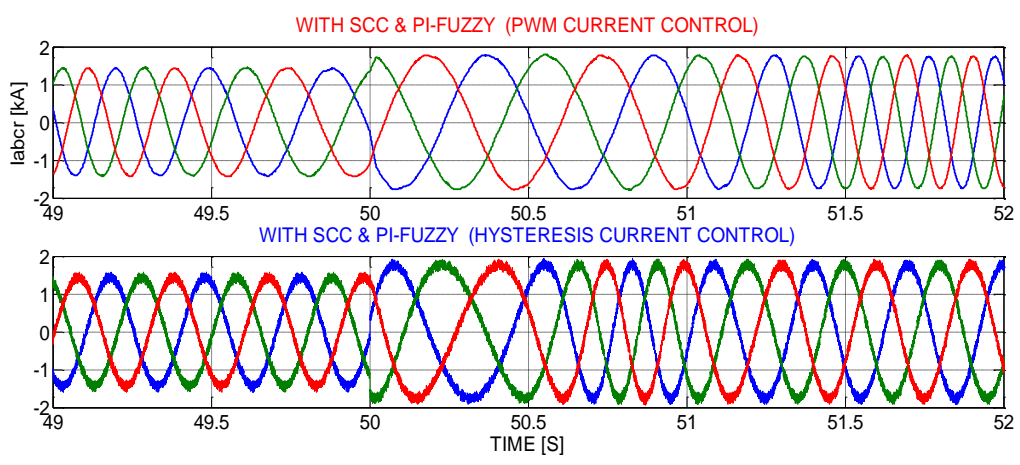

Fig. 8. Rotor current during transient state.
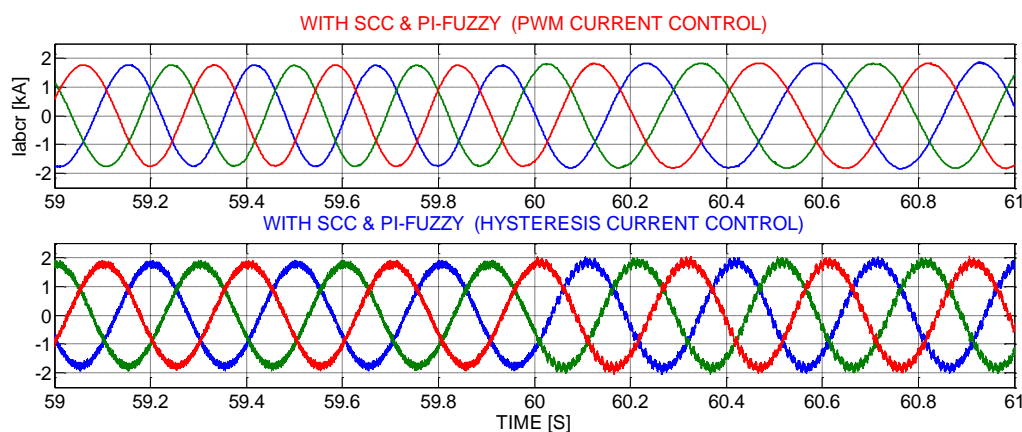

Fig. 9. Rotor current during unbalanced voltage (unbalanced again from the 60th second).
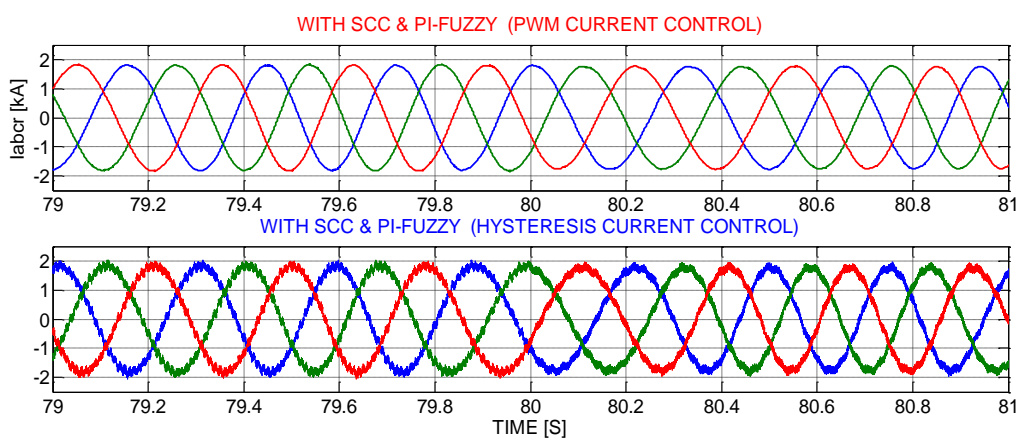

Fig. 10. Rotor current during unbalanced voltage (balanced again from the 80th second).

During the unbalanced voltage, best performances of active power are observed for SCC \& PI-F (PWM), then with SCC \& PI-F(HCC). In detail, the lowest value of $P_{\text {Max }}$ for SCC \& PI-F(HCC) is $-1 \%$ of the commanded value. The highest value of $P_{\text {Min }}$ for the for SCC \& PI-F (HCC) $\approx 0 \%$ of the set value Fig. 11 to Fig. 13.
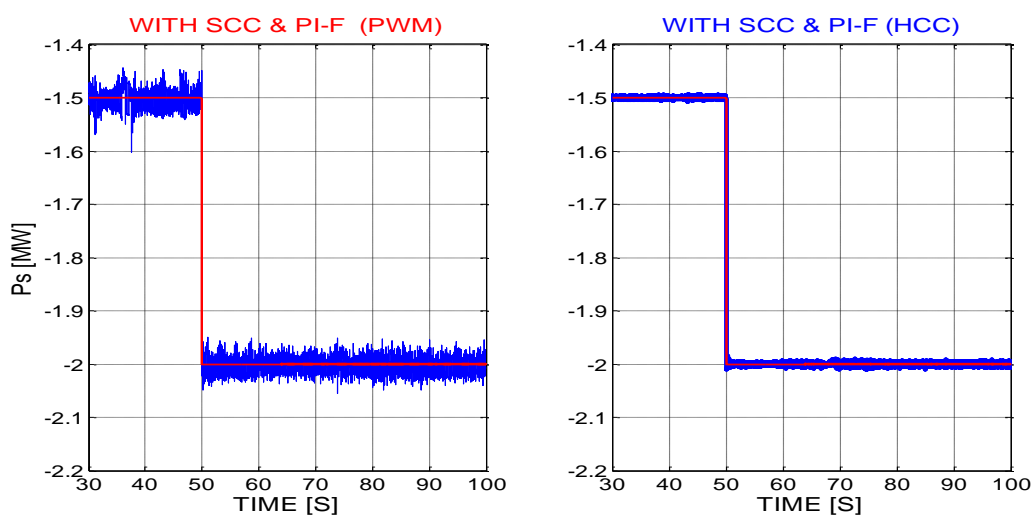

Fig. 11. Active output power of DFIG. 

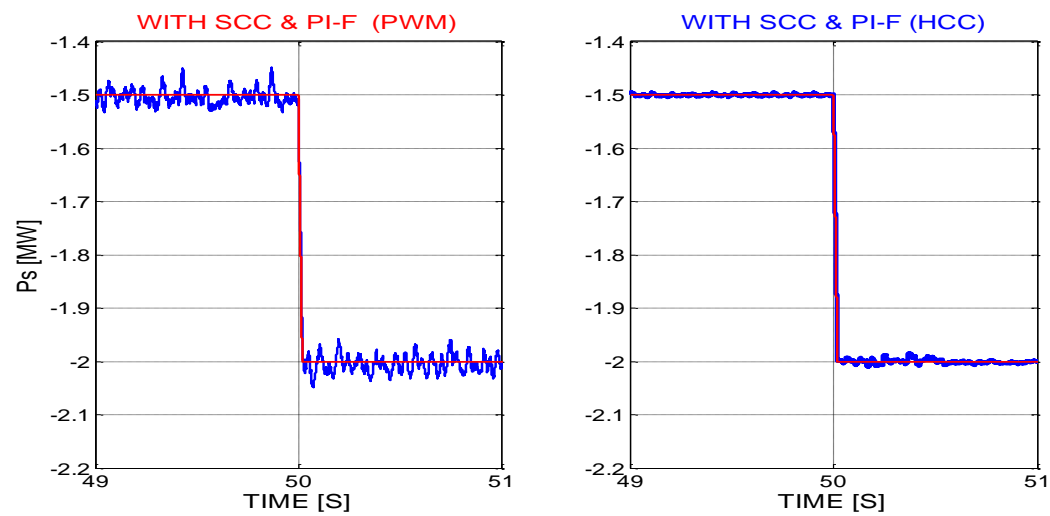

Fig. 12. Active power during transient state.
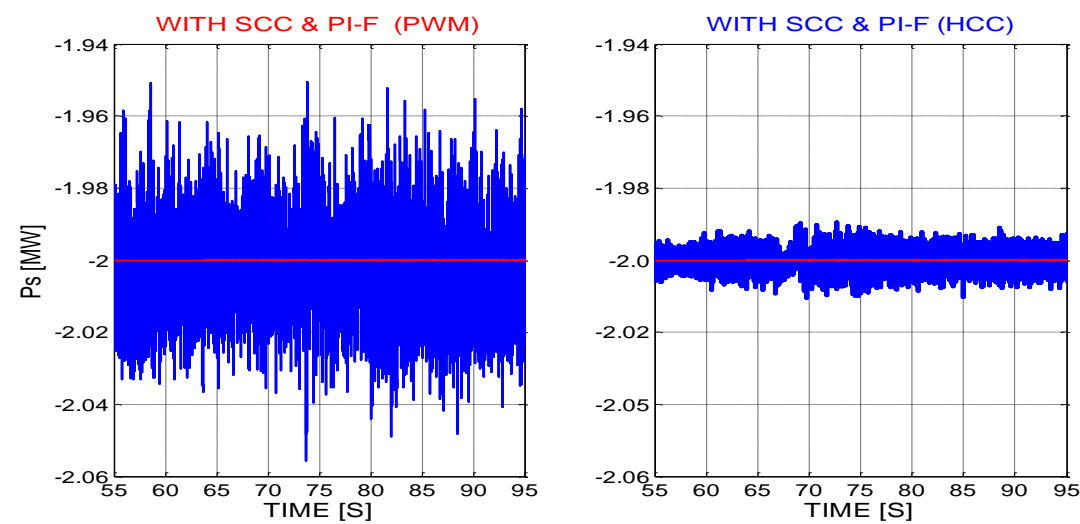

Fig. 13. Active power during unbalanced voltage.

During the unbalanced voltage, best performances of reactive power are observed for for SCC \& PI-F (PWM), then with SCC \& PI-F (HCC). In detail, the lowest value of QMax for SCC \& PI-F (HCC) is - $1 \%$ of the commanded value. The highest value of $Q_{\text {Min }}$ for the for SCC \& PI-F (HCC) is $-2 \%$ of the set value, Fig. 14 to Fig. 16.

The simulation results with two different control structures, including the proposed scheme, are shown in Fig. 11 to Fig. 19 for the active and reactive output powers. These figures demonstrate the power responses when the voltage unbalance happens (from the time $t=60 \mathrm{~s}$ ) and when the commanded values of powers change (at the time $t=50 \mathrm{~s}$ ) under the voltage unbalance. Besides, Fig. 17, Fig. 18 illustrates the torque response of the generator.
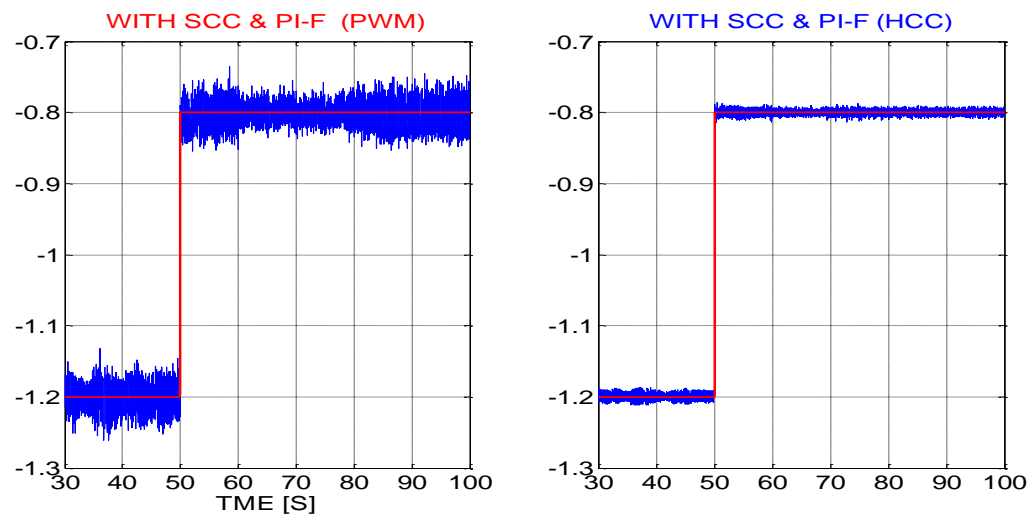

Fig. 14. Reactive output power of DFIG. 

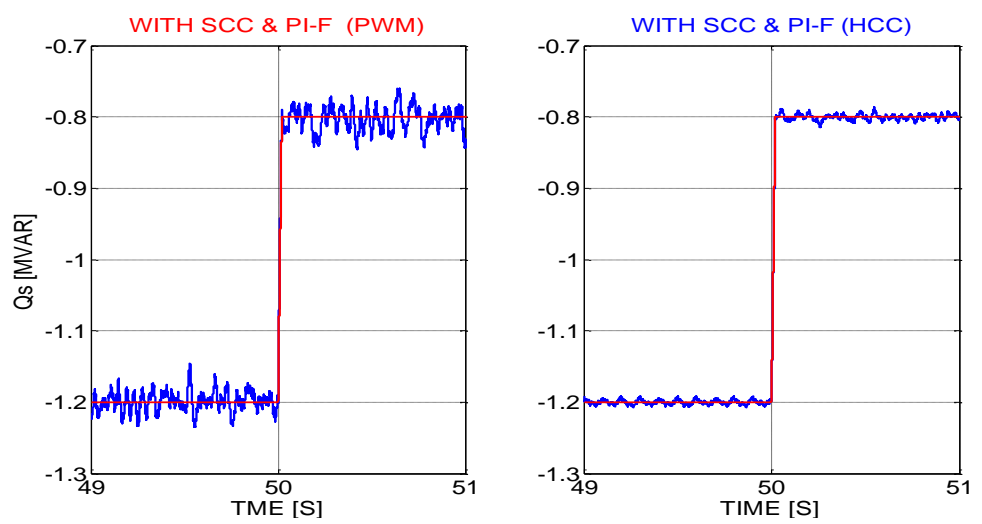

Fig. 15. Reactive power during transient state.
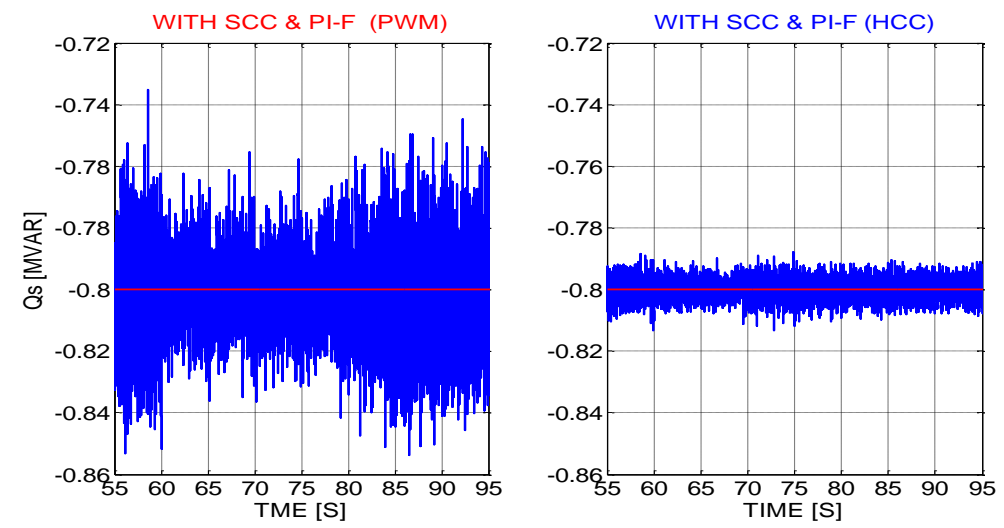

Fig. 16. Reactive power during unbalanced voltage.
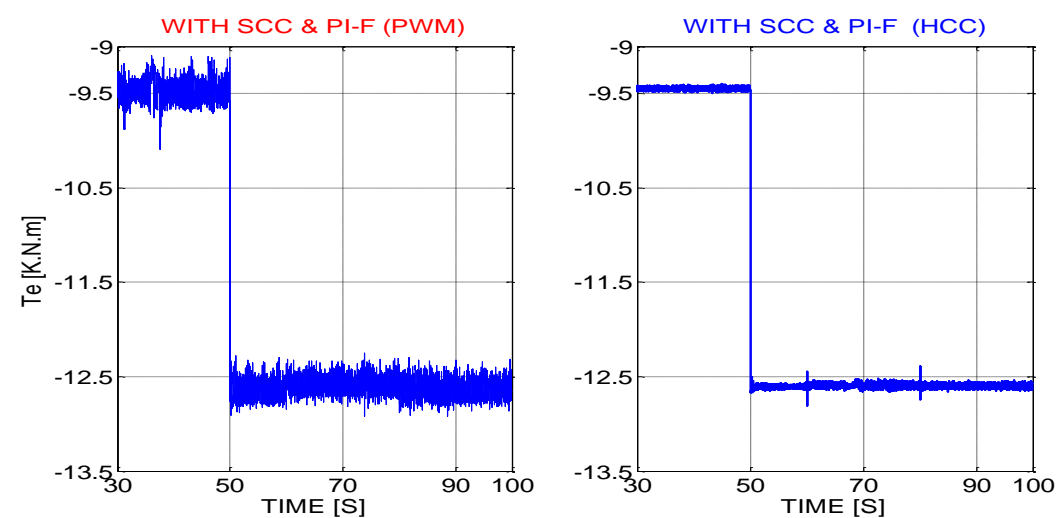

Fig. 17. Torque output power of DFIG.
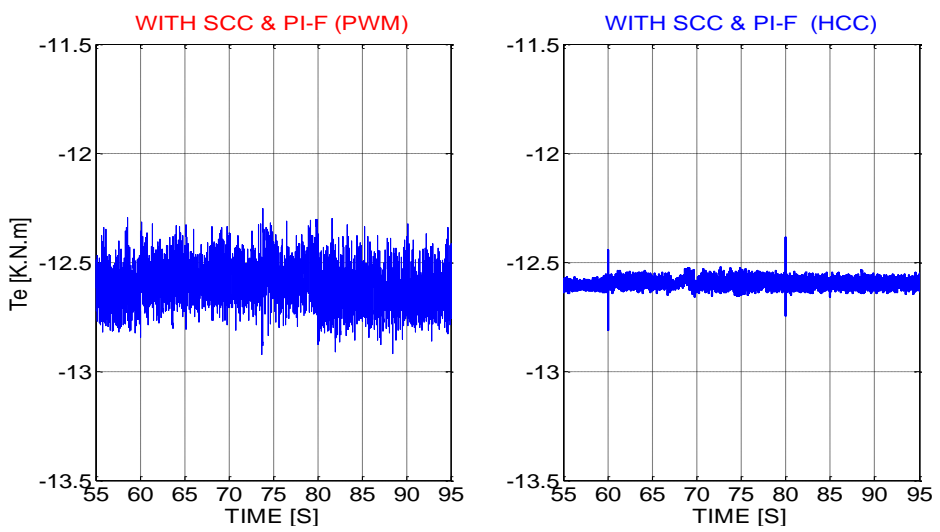

Fig. 18. Torque during transient state. 


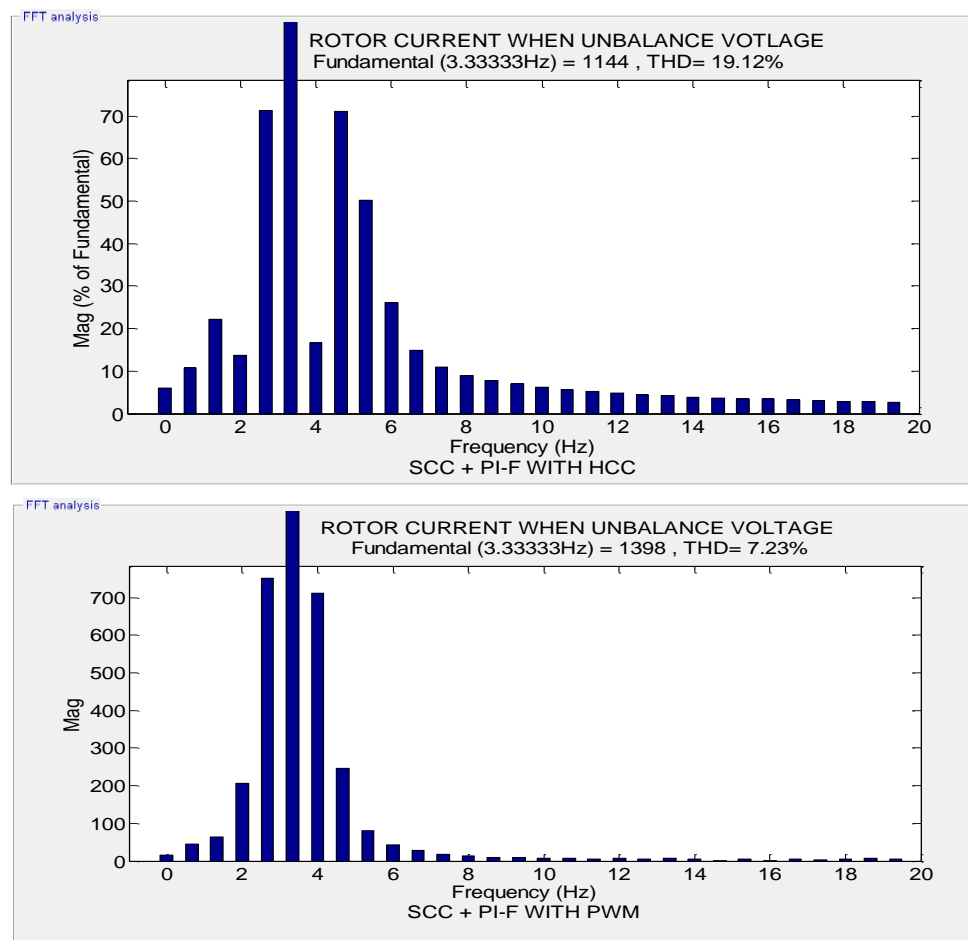

Fig. 19. THD's rotor current when unbalance voltage.

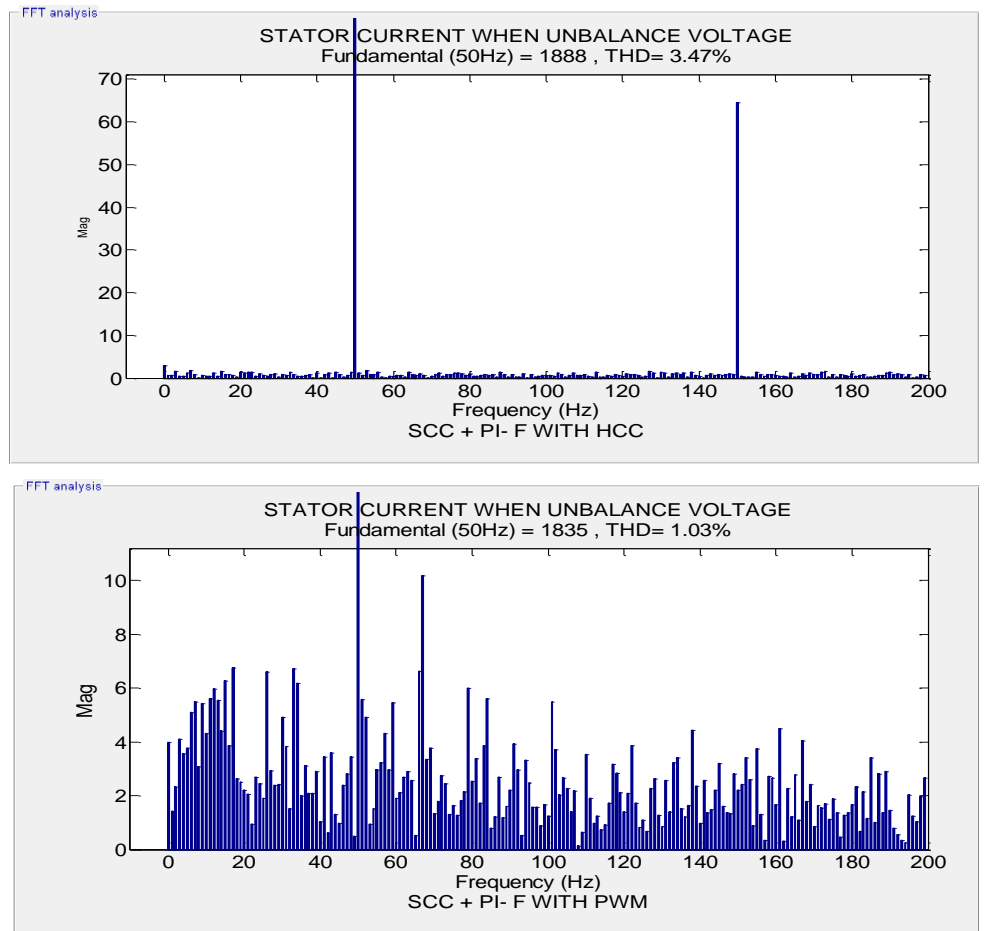

Fig. 20. THD ‘s stator current when unbalance voltage.

\section{Dicussion}

As shown in Table 2, the SCC using PI-F (HCC) methods have shown good steady-state active power responses during the voltage unbalance. In detail, the deviation of the mean value of active power from the reference value is almost zero percent; and the deviation of the maximum and minimum values from the mean value are within 1\%. In addition, SCC using PI-F (PWM) is also giving the good performance with 
small deviation of mean values from reference values about $3 \%$.

The PWM schemes is active power response when the voltage unbalance happens has higher ripples, while the responses obtained with the two SCC using PI-F for HCC schemes.

As seen in Table 3, steady-state responses of the reactive power are also very good with SCC using PI-F (HCC). In detail, the deviations are $\pm 2 \%$. Besides, the deviations of reactive power's mean values for SCC using PI-F (HCC) are also reasonably small during the voltage unbalance. Additionally, higher ripples are observed in reactive power responses of the traditional PI when the voltage unbalance occurs as described in Fig. 14 to Fig. 16. The observation is also consistent with statistics in Table 3. Fig. 15 and Fig. 16 shows the dynamic responses of reactive powers during transient states.

The SCC using PI-F (PWM) is rotor current response when the voltage unbalance happens has higher ripples, while the responses obtained with the two SCC using PI-F (HCC) schemes (shows in Fig. 8 to Fig. $10)$.

Harmonic contents of stator current during balanced voltage are quite good for the two control schemes above as shown in Fig. 19 and Harmonic contents of rotor current in Fig. 20. The Total Harmonic Distortion's (THD) are almost the same in these figures. However, during voltage unbalance, with PWM current control gives the best performance in terms of THD. Table 4 illustrates the comparison of THD in the two methods for unbalanced voltages.

Table 4. Thd Comparison for Stator and Rotor Current when Unbalance Voltage

\begin{tabular}{|c|c|c|}
\hline THD & SCC+ PI-F + PWM & SCC + PI-F+HCC \\
\hline Stator current $(\mathrm{f}=50 \mathrm{~Hz})$ & $\mathbf{1 . 0 3 \%}$ & $3.47 \%$ \\
\hline Rotor current $(\mathrm{f}=10 / 3 \mathrm{~Hz})$ & $\mathbf{7 . 2 3} \%$ & $19.21 \%$ \\
\hline
\end{tabular}

Total harmonic distortion of the two new control schemes for stator current has been significantly reduced during the unbalanced voltage $(1.03 \%$ for PWM and $3.47 \%$ for HCC). For THD's rotor current (7.23\% for PWM and 19.21\% for HCC). All the THD values of stator current are increased during the unbalance

\section{Conclusion}

The proposed SFOC-based scheme for DFIG with the inclusion of SCC has elevated the stability of the torque response during the grid voltage unbalance when being compared with other modifications of PWM and HCC for better stabilities during the unbalanced voltage dip. This improvement helps reduce the electrical stress on converters and the mechanical stress on the gear box. Furthermore, the responses of active and reactive power are ameliorated when being compared with a traditional SFOC, although the oscillations are still quite high.

In this study, the observations are made during the occurrence of the voltage dip in one phase, transient states as well as steady states of the powers and torque under the unbalanced condition. When being compared with responses from HCC, the proposed scheme also gives fast responses of active and reactive powers during transient states under the voltage unbalance. In all the observations, the independent controls of the powers are still maintained for the suggested scheme.

Responses of the active power, reactive power, and torque from all the control schemes are observed at the sub-synchronous speed operation when the active power is consumed on the rotor and delivered on the stator of DFIG.

In the future, the experimental verification of the proposed control scheme should be carried out to validate the results obtained in simulations 


\section{Appendix}

$\begin{array}{ll}v_{s}, v_{r} & \text { Stator, rotor voltage vectors. } \\ i_{s}, i_{r} & \text { Stator, rotor current vectors. } \\ \psi_{s}, \psi_{r} & \text { Stator, rotor flux vectors. } \\ \omega_{s} & \text { Stator angular frequency. } \\ \omega_{r} & \text { Rotor speed. } \\ P_{s}, Q_{s} & \text { Stator output active and reactive power. } \\ L_{m} & \text { Mutual inductance. } \\ L_{\sigma s}, L_{\sigma r} & \text { Stator, rotor leakage inductances. } \\ L_{s}, L_{r} & \text { Stator, rotor self inductances. } \\ R_{s}, R_{r} & \text { Stator, rotor resistance } \\ \theta_{r} & \text { Rotor angle } \\ \theta_{s} & \text { Stator flux angle in SFOC } \\ \theta_{s l} & \text { Slip angle, } \theta_{s l}=\theta_{s}-\theta_{r}\end{array}$

\section{Superscripts}

,$+-\quad$ Positively, negatively $(\mathrm{dq})$ rotating reference frames.

* $\quad$ Reference value for controllers.

\section{Subscripts}

$\begin{array}{ll}\alpha, \beta & \text { Stationary } \alpha-\beta \text { axis. } \\ \alpha_{r}, \beta_{r} & \text { Rotor } \alpha_{r}-\beta_{r} \text { axis. } \\ d, q & \text { Rotating } d-q \text { axis. } \\ s, r & \text { Stator, rotor. } \\ +,- & \text { Positive, negative components }\end{array}$

\section{References}

[1] Ackermann, T. (2003). Wind Power In Power Systems. John Wiley and Sons.

[2] Leonhard, W. (2001). Control of Electric Drives (3rd ed.). Springer-Verlag.

[3] Wenske, J. (2011). Special report direct drives and drive-train development trends. Wind Energy Report Germany 2011. Siemens Press Picture.

[4] Alegría, M. I., Andreu, J., Martín, L. J., Ibanez, P., Villate, L. J., \& Camblong, H. (2007) Connection requirement for wind farms: A survey on technical requirements and regulation. Renewable and Sustainable Energy Review, 11(8), 1858-1872.

[5] Muljadi, E., Yildirim, D., Batan, T., \& Butterfield, C. P. (1999). Understand the unbalanced-voltage problem in wind turbine generation. Proceedings of IEEE Industry Application Conference (pp. 1359-1365). Phoenix, USA.

[6] Xu, L., \& Wang, Y. (2007). Dynamic modeling and control of DFIG based wind turbines under unbalanced network conditions. IEEE Transactions of Power Systems, 22(1), 314-323.

[7] Yikang, H., Jiabing, H., \& Rende, Z. (2005). Modelling and control of wind-turbine used DFIG under network fault conditions. Proceedings of the Eight International Conference on Electrical Machines and Systems (pp. 986-991), Nanjing, China. 
[8] Jiabing, H., Yikang, H., Lie, X., \& Williams, W. B. (2009). Improve control of DFIG systems during network unbalance using PI-R current regulators. IEEE Transactions on Industrial Electronics, 56(2), 439-451.

[9] Pham-Dinh, T., Nguyen, A. N., \& Nguyen-Thanh, H. (2012). Improving stability for independent power control of wind turbine doubly fed induction generator with SFOC and DPC during grid unbalance. Proceedings of the 10 $10^{\text {th }}$ International Power and Energy Conference (pp. 155-160). Ho Chi Minh City, Vietnam.

[10] Jiabing, H., \& Yikang, H. (2009). Modelling and enhance control of DFIG under unbalanced grid voltage conditions. Electric Power Systems Research, 79(2), 272-281.

[11] Pham-Dinh, T., Nguyen-Thanh, H., Uchida, K., \& Nguyen, G. M. T. (2013). Comparison between modifications of SFOC and PDC in control of grid-connected doubly fed induction generator under unbalanced voltage dip. Proceedings of SICE Annual Conference (pp. 2581-2588). Nagoya, Japan.

[12] Pham-Dinh, T., \& Nguyen-Thanh, H. (2013). Improving stability for independent power control of wind-turbine doubly fed induction generator during grid unbalance with PI-Fuzzy controller. Journal of the Japan Society of Applied Electromagnetics and Mechanies, 21(3), 425-429.

[13] Ghennam, T., Berkouk, E. M., \& Francois, B. (2007). A vector hysteresis current control applied on three-level inverter. application to the active and reactive power control of doubly fedinduction generator based wind turbine. International Review of Electrical Engineering.

[14] Srinadh, J. (2014 July). Dynamic performance of DFIG using SMES for WECS. International Journal of Recent Development in Engineering and Technology, 3(1), 148-155.

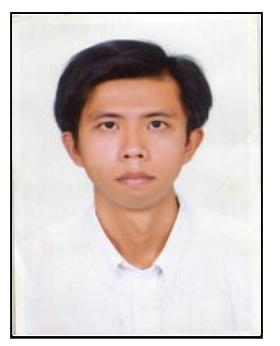

Hai Nguyen-Thanh was born in 1978 in Ho Chi Minh City, Vietnam. He received his B.S. and M.S. degrees from Hochiminh City University of Technology, Vietnam, in 2000 and 2012, respectively. He is currently a Ph.D. student at HCMC University of Technical and Education, Vietnam. He is a member of IEEE, SCIEI, IACSIT. His research interests are wind power generation, intelligent control, and renewable energy system. 